\title{
Design de superfície têxtil: um estudo sobre o conhecimento geométrico presente nos Freedom Quilts
}

Textile surface design: a study of the geometrical knowledge in African American Freedom Quilts

\section{Franciele Menegucci \\ Mestre em Design - UNESP (Bauru) franciele_menegucci@yahoo.com.br}

Edna Martins Mestre em Design - UNESP (Bauru) martinnsedna@yahoo.com.br

\section{Marizilda dos Santos Menezes}

Doutorado em Estruturas Ambientais Urbanas pela Faculdade de Arquitetura e Urbanismo - USP marizilda.menezes@gmail.com 


\section{Design de superfície têxtil: um estudo sobre o conhecimento geométrico presente nos Freedom Quilts}

Textile surface design: a study of the geometrical knowledge in African American

Freedom Quilts

Franciele Menegucci, Edna Martins e Marizilda dos Santos Menezes

\section{Resumo}

Este artigo aborda a presença de conhecimentos materiais, técnicos e tecnológicos originários da cultura africana em trabalhos de superfície e construção têxtil por meio da análise de padrões geométricos e as composições deles derivadas, presentes em trabalhos com a técnica de quilt. Esta relação é discutida sob a perspectiva da geometria e do design de superfície têxtil evidenciando como a reflexão sobre a diversidade étnica e cultural pode contribuir com a afirmação e valorização de determinadas culturas e de seus conhecimentos que, em muitos momentos, são desenraizados e erroneamente atribuídos a culturas europeias e euro descendentes. Neste artigo busca-se evidenciar a origem africana de alguns padrões geométricos ricamente projetados em superfícies têxteis, muitas vezes reproduzidos, ensinados e disseminados sem que lhes sejam conferidas as devidas procedências. Esta reflexão demonstrará as contribuições da cultura africana e afrodescendente no design de superfície têxtil, legitimando a sistematização do saber e do conhecimento africano que pode ser compreendida por meio do estudo de seus artefatos.

Palavras- chave: design de superfície têxtil; conhecimento; padrões afrodescendentes

\begin{abstract}
This paper discusses the presence of materials, technical and technological knowledge originating in the African culture in surface and textile construction work through the analysis of geometric patterns and their compositions derived, present in work with the quilt technique. This relationship is discussed from the perspective of geometry and the textile surface design showing how reflection on the ethnic and cultural diversity can contribute to the affirmation and appreciation of certain crops and their knowledge that, in many instances, are rootless and wrongly attributed the European and euro descendants cultures. This paper seeks to highlight the African origin of some geometric patterns lavishly designed in textile surfaces, often played, taught and disseminated without their proper provenances are granted. This reflection will demonstrate the contributions of African culture and African descent in the textile surface design, legitimizing the systematization of knowledge and African knowledge that can be understood through the study of its artifacts.
\end{abstract}

Keywords: Surface textile design; knowledge; African and Afro-descendant culture 


\section{Introdução}

Formas e conceitos geométricos relacionam-se profundamente com a humanidade. Sua presença no ambiente, na configuração de plantas, animais, minerais e no próprio corpo humano podem ser responsáveis pelo emprego da geometria em artefatos e técnicas artesanais, reproduzidas em superfícies nas cerâmicas, cestarias e na tecelagem, entre outras. Tratam-se de formas presentes no consciente e no inconsciente humano, nas mais diversas culturas e etnias (DOCZI, 2008).

O design de superfície têxtil e suas respectivas técnicas, como a tecelagem, a estamparia, os bordados, as aplicações e as costuras estão vinculadas ao fazer manual, mesmo que desenvolvidos industrialmente, tem origem nos afazeres domésticos. Entre estes encontra-se o quilt, apesar de suas imagens serem aplicadas industrialmente em estampas, a técnica encontra-se no domínio das manualidades.

As superfícies têxteis tradicionais possuem inter-relações com os conhecimentos geométricos. Na produção de panos africanos tradicionais é possível verificar o emprego da geometria na composição de superfícies. Em um estudo a partir da etnogeometria, Menezes (2005) verificou a ocorrência das transformações geométricas nas técnicas de tecelagem, tingimento, estamparia e bordados evidenciando o apuro estético e tecnológico utilizado no planejamento destes materiais.

Com a perspectiva de estabelecer a presença da diversidade étnica e cultural na composição de quilts, este artigo aborda os conhecimentos materiais, técnicos e tecnológicos originários da cultura africana em trabalhos de superfície e construção têxtil por meio da análise de padrões geométricos e as composições deles derivadas, presentes em trabalhos com a técnica de quilt. Esta relação é discutida sob a perspectiva da geometria e do design de superfície têxtil evidenciando como a reflexão sobre a diversidade étnica e cultural pode contribuir com a afirmação e valorização de determinadas culturas e de seus conhecimentos que, em muitos momentos, são desenraizados e erroneamente atribuídos a culturas europeias e euro descendentes.

Neste artigo busca-se apresentar a origem africana de alguns padrões geométricos ricamente projetados em superfícies têxteis, muitas vezes reproduzidos, ensinados e disseminados sem que lhes sejam conferidas as devidas procedências. Esta reflexão demonstrará as contribuições da cultura africana e afrodescendente no design 
de superfície têxtil, legitimando a sistematização do saber e do conhecimento africano que pode ser compreendida por meio do estudo de seus artefatos.

\section{Abordagem metodológica}

Este artigo foi elaborado por meio de pesquisa qualitativa que, para Minayo (1994, p. 7), responde a questões muito particulares nas ciências sociais, com um nível de realidade que não pode ser quantificado, "trabalha com o universo de significados, motivos, aspirações, crenças, valores e atitudes, o que corresponde a um espaço mais profundo das relações, dos processos e dos fenômenos".

Os métodos selecionados são a pesquisa bibliográfica e exploratória, realizadas em duas etapas. Na primeira etapa foram estudadas as bases teóricas de forma a adquirir recursos para análise e discussão, investigando-se: o design de superfície têxtil; os quilts africanos e afro-descendentes em seu contexto histórico e cultural e os conceitos geométricos presentes nas composições. Na segunda etapa, foi realizada a análise iconográfica de blocos de quilt de origem africana e afrodescendente, para verificar as ocorrências de transformações geométricas presentes nos blocos e em suas aplicações em peças artesanais. A análise dos blocos e de suas composições foi realizada com base na metodologia utilizada por Menezes (2005) que averiguou a ocorrência de transformações geométricas em panos africanos nas técnicas de estamparia, tecelagem, tingimento e bordado para, posteriormente, discutir o legado desta cultura quanto a técnicas e tecnologias de produção aplicáveis ao design. Esta metodologia pautou-se em Gerdes (1992, p. 99 apud MENEZES, 2005) na qual o autor propõe que os povos que possuem tradição oral e não escrita, podem ter seus pensamentos geométricos estudados por meio de suas obras, ou seja, os objetos por eles produzidos.

\section{Bases teóricas}

\subsection{Os quilts}

Os quilts caracterizam uma técnica artesanal realizada a partir do uso de pedaços de tecidos unidos (top), mantas de acolchoamento (batting), forro (backing), costura e acabamentos nas laterais (binding).

Muitas vezes o termo patchwork acompanha suas definições, pois o termo patch, em língua portuguesa significa as ações de alinhavar, remendar, arranjar e, como 
substantivo, pode ser traduzido como remendo, fragmento, já a palavra work, como substantivo significa trabalho. Assim, no contexto do artesanato, a prática de patchwork pode ser compreendida como trabalho com remendos ou alinhavos, este trabalho não precisa necessariamente estar atrelado ao forro e ao acolchoamento. O patchwork diz respeito à superfície ou topo e pode ser usado para a confecção de acessórios, vestuários e artigos para casa. Esse topo é também utilizado na elaboração do quilt. O termo quilt, como verbo, significa acolchoar, estofar. Com a junção do topo, da manta e do forro, por meio da costura, manual ou à máquina, que une as três camadas, tem-se o quilt, que define o trabalho já finalizado. Já o quilting, é a prática de realizar o quilt. Assim neste trabalho optou-se pelo uso do termo quilt pois este relaciona-se ao trabalho já finalizado (VAN HAEFF; FLEW, 2006).

O termo quiltar, relaciona-se a técnica de unir com pespontos materiais têxteis de várias espessuras, acolchoando o trabalho, essa técnica pode ter surgido antes do surgimento dos tecidos, a partir da emenda de peles de animais (PEZZOLO, 2007).

Na prática do quilt tradicional destaca-se a perspectiva projetual que planeja a disposição das formas e das cores, bem como os conceitos de superfície, como módulos, padrões e simetrias, já alguns trabalhos artesanais com remendos não possuem essa característica.

$\mathrm{Na}$ cultura brasileira, a prática do quilt tem se expandido nos últimos anos, o apogeu da internet ajudou a disseminar a técnica em grupos virtuais de artesanato e, esporadicamente, é aplicado a produtos de moda (Figura 1), composto por materiais diversos. Erroneamente disseminou-se a ideia de que se trata de uma técnica de origem norte-americana, em parte devido ao fato de ser amplamente praticada nos Estados Unidos. 
Figura 1 - Quilt utilizado como inspiração no design de moda

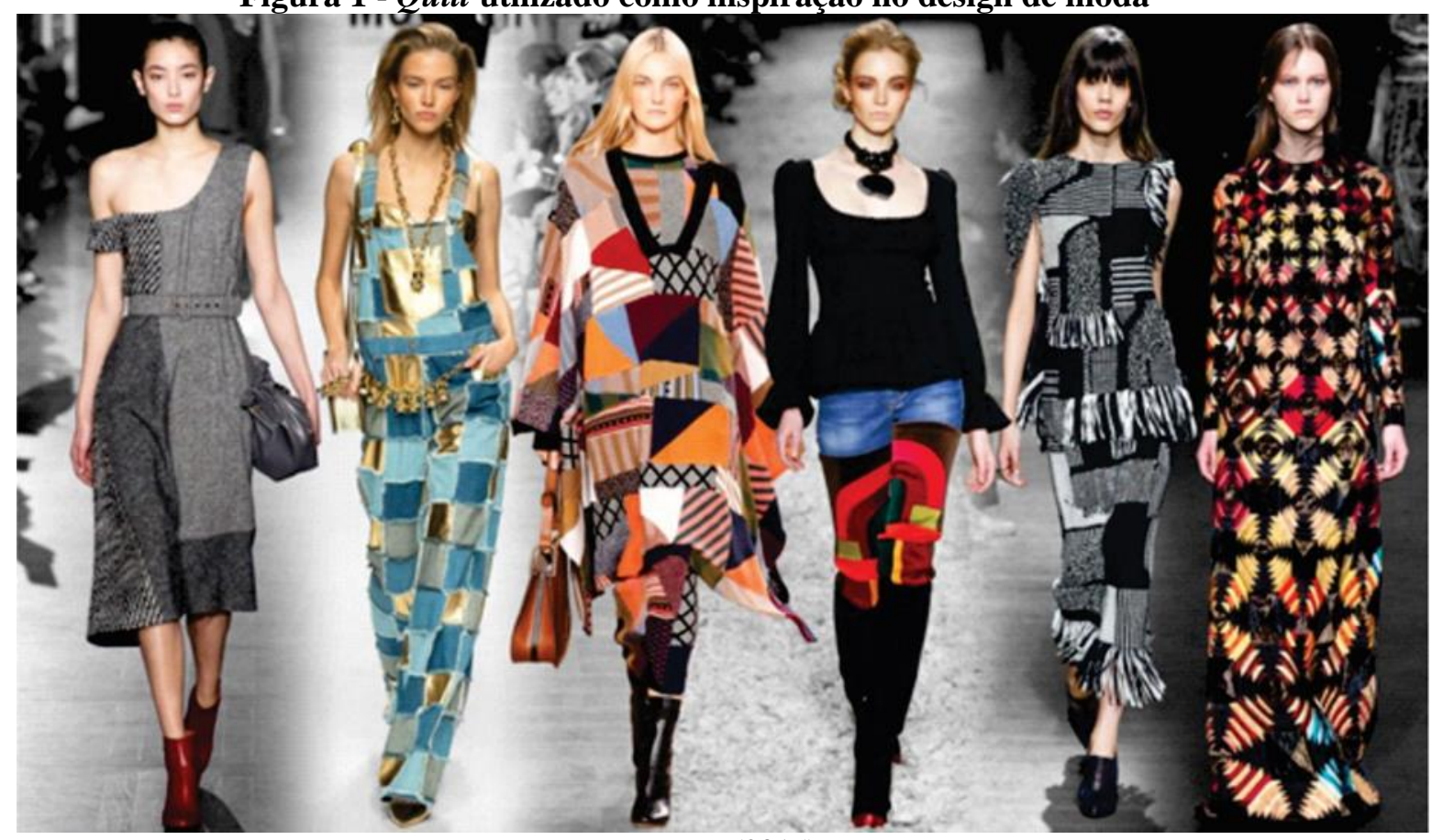

Fonte: Fung (2015)

Para Wertkin (2004) esta técnica foi trazida do Oriente Médio para a Europa, ao fim do século XI, com as Cruzadas. Já na Idade Média, por baixo das armaduras, era costume vestir roupas acolchoadas com o intuito de obter conforto e proteção. No acervo do Victoria and Albert Museum, encontra-se uma colcha produzida pela técnica de quilt. Sua produção é atribuída à região da Sicília, entre 1360 a 1400, possui o linho como material de topo, a lã como preenchimento e seus blocos exibem a lenda de Tristão. 
Figura 2 - Colcha em quilt de origem siciliana

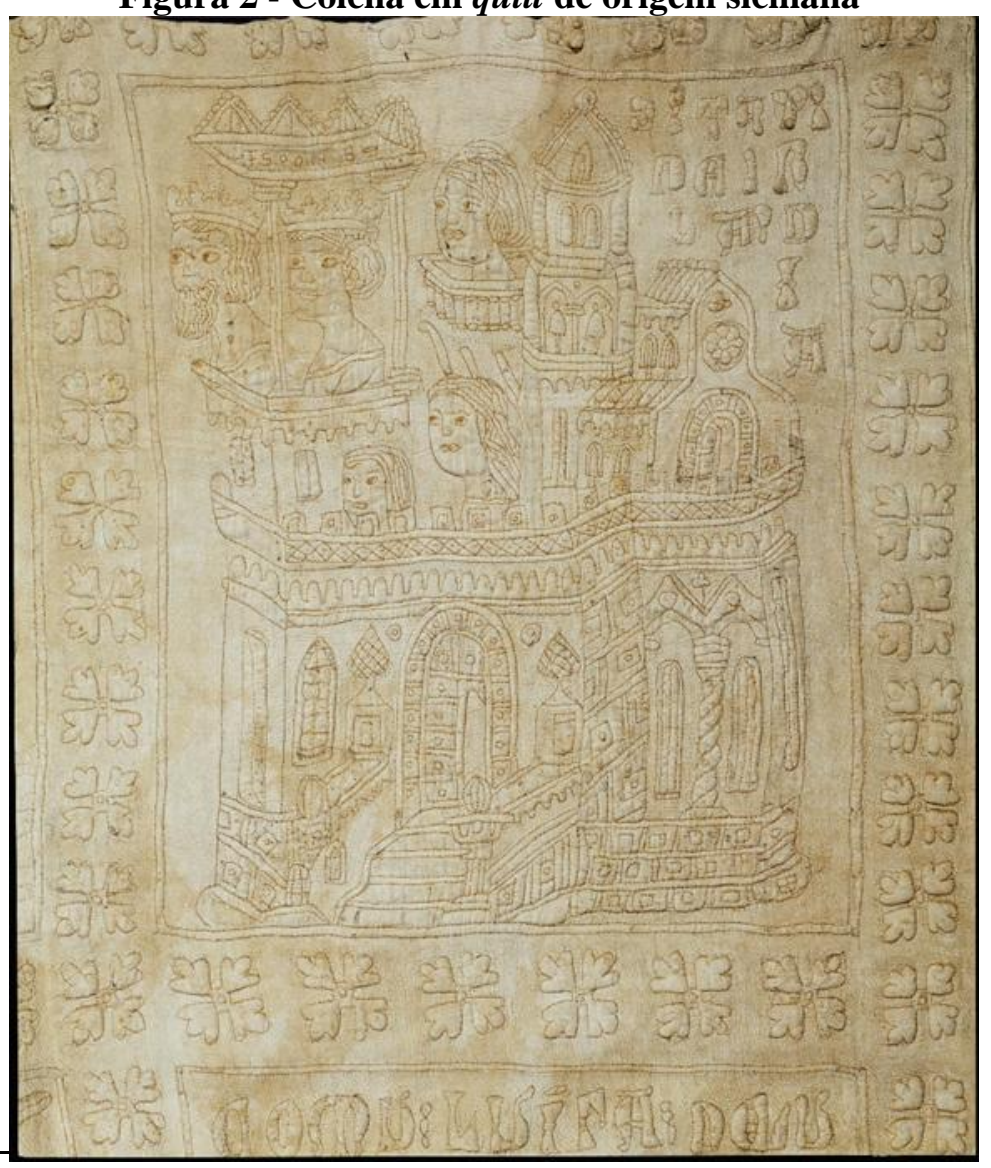

Fonte: Victoria and Albert Museum (2015)

Johnson (2015) afirma que foram os colonizadores que introduziram o quilt na América, estes teriam trazido consigo muito do patrimônio cultural europeu. No século XIX, a técnica prosperou, sobretudo entre 1825 e 1875. O quilting se adaptou bem às Grandes Planícies do Oeste americano e tornou-se importante para os colonos sendo usados em artefatos para o lar. Os amplos espaços abertos e o relativo isolamento das Grandes Planícies fizeram surgir os quiltings bees, uma reunião de mulheres onde cada uma trazia seus topos em previamente remendados para juntas acolchoá-los, era uma oportunidade de socialização feminina.

Neste artigo é fundamental refletir sobre outro ângulo da história do quilt, pouco disseminada em território brasileiro, este diz respeito a execução do quilting como uma ferramenta de comunicação por afro-americanos que escaparam da escravidão antes da Guerra Civil dos Estados Unidos (1861-1865). O Underground Railroad, como o período ficou conhecido, refere-se a rede de abolicionistas e casas seguras que auxiliavam os escravos a fugirem para Ohio e Canadá. As "estações" eram as casas 
seguras, "condutores" eram aqueles que guiavam os fugitivos e os "passageiros" eram os escravos que buscavam pela liberdade. Os trabalhos conhecidos como Freedom Quilts eram colchas e outros artefatos domésticos pendurados em varais, varandas e janelas que traziam indicações sobre o que fazer ou para onde ir, usando diferentes desenhos que indicavam segurança, perigo, pistas e pontos de referência para orientar até a liberdade. As colchas foram costuradas para servir como um mapa codificado por escravos fugitivos, com afirmam Rosa e Orey (2009).

Os blocos tradicionais e também os Freedom Quilts possuem formas geométricas que, ao serem unidas por costura, compõem um quadrado com medidas aproximadas de vinte e quarenta centímetros. O bloco denominado Nine Patch (nove remendos/fragmentos) é obtido por meio da união de cinco partes com determinada estampa ou cor e quatro de outra estampa ou cor, podendo haver variações no número de cores. Muitos blocos são derivações do Nine Patch (SIELERT, 2015). Blocos com as mesmas dimensões, porém com grades de quatro são denominados Four Patch (Figura 3).

Figura 3 - Blocos Nine Patch e Four Patch e suas variações

Nine patch e variações
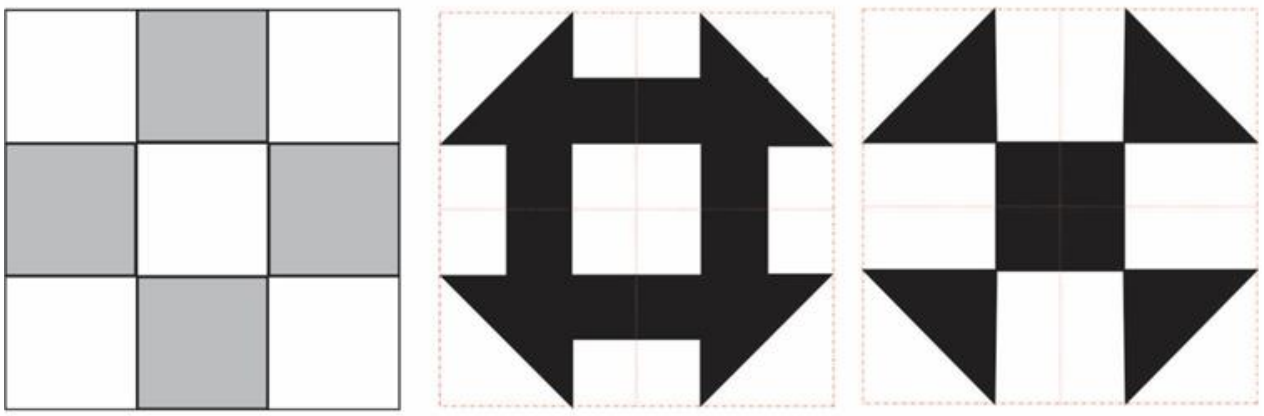

\section{Four patch e variações}

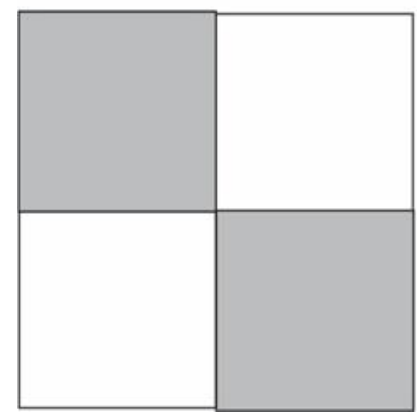

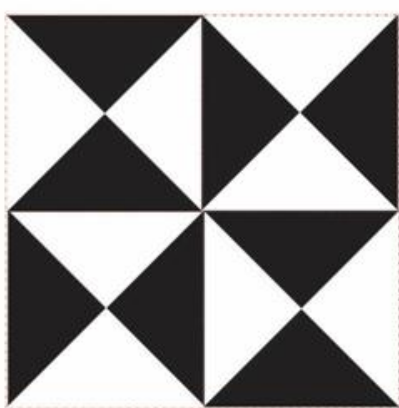

Fonte: autora (2016)

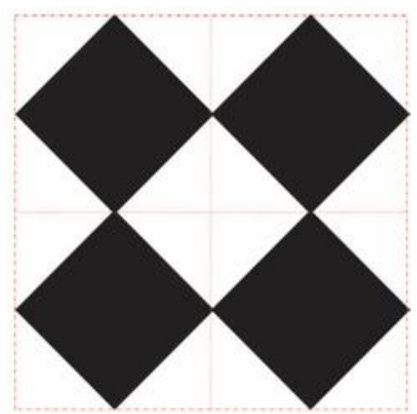


Outra perspectiva que deve ser considerada é que tais códigos secretos remontam à tradição africana de imprimir codificação aos seus têxteis, assim, o projeto geométrico em tecidos pode ter sido levado as Américas pelos africanos (EGLASH, 2002 apud ROSA; OREY, 2009). Como os escravos eram impedidos de utilizar seus próprios símbolos em artesanatos, adotaram os padrões americanos de significados e passaram a utilizá-los para a comunicação. A simbologia presente nos quilts foi esclarecida por Ozella McDaniels Williams, uma artesã afro-americana. Ela identificou pelo menos dez padrões usados como códigos (Figura 4).

Figura 4 - Padrões identificados por Ozella McDanie Williams

\begin{tabular}{|c|c|c|c|}
\hline Descrição & Bloco & Descrição & Bloco \\
\hline $\begin{array}{l}\text { Bear Paw (Pata de urso) } \\
\text { Indicava a encontrar uma trilha } \\
\text { na montanha e seguir o caminho } \\
\text { feito por pegadas de ursos que } \\
\text { levariam a água e comida }\end{array}$ & & $\begin{array}{l}\text { Flying geese (vô̂ de ganso) } \\
\text { Siga a direção dos gansos na } \\
\text { migração de primavera }\end{array}$ & \\
\hline $\begin{array}{l}\text { Monkey wrench (chave } \\
\text { inglesa) } \\
\text { Indicava que deviam reunir as } \\
\text { ferramentas/ equipamentos } \\
\text { necessários para uma longa } \\
\text { viagem }\end{array}$ & & $\begin{array}{l}\text { Shoo fly } \\
\text { É possível identificar um guia } \\
\text { amigável que fica nas } \\
\text { proximidades e pode ajudar }\end{array}$ & \\
\hline $\begin{array}{l}\text { Bow tie (gravata borboleta) } \\
\text { Indicava que se vestissem como } \\
\text { libertos, disfarçados }\end{array}$ & & $\begin{array}{l}\text { Follow the stars (siga as } \\
\text { estrelas) } \\
\text { Indicava que deveriam seguir } \\
\text { certas constelações ou estrelas } \\
\text { específicas ensinadas aos } \\
\text { fugitivos }\end{array}$ & \\
\hline $\begin{array}{l}\text { Crossroads (encruzilhada) } \\
\text { Indicava o lugar onde os } \\
\text { caminhos se fundiam. } \\
\text { Cleveland, Ohio, é } \\
\text { historicamente o fim da estrada } \\
\text { de ferro subterrânea }\end{array}$ & & $\begin{array}{l}\text { Log Cabin (cabana de } \\
\text { madeira) } \\
\text { Indicava uma casa segura ou } \\
\text { uma casa para evitar, conforme } \\
\text { as cores }\end{array}$ & \\
\hline $\begin{array}{l}\text { Follow the stars (siga as } \\
\text { estrelas) } \\
\text { Variação do bloco follow the star }\end{array}$ & & $\begin{array}{l}\text { Drinkards (Bêbado) } \\
\text { Indicava que deviam despistar } \\
\text { suas pegadas }\end{array}$ & \\
\hline
\end{tabular}

Fonte: Adaptado de Rosa e Orey (2009, p. 60) 
Os padrões tinham duas funções principais, um sinal para que os escravos se preparassem para a fuga e pistas para indicar direções seguras, conforme acreditam alguns pesquisadores (ROSA; OREY, 2009).

A história dos quilts e sua relação simbólica com o Underground Railroad é confirmada por pesquisadores como Eglash (2002) e Rosa e Orey (2009), outros questionam o emprego dos códigos, como Blight (2004) e Raw (2009). Porém, é certo que aspectos da cultura material africana, seus sinais e símbolos foram empregados em quilts elaborados por afrodescentes na América, essa transposição é estudada e apresentada por Wahlman (2001) que afirma que os quilts afro-americanos assemelhamse ao jazz, ao blues e ao gospel, ricos em cor e simbolismo tem suas raízes nas técnicas têxteis africanas e em sua tradição. Essa relação foi traçada entre os anos 1650 e 1850, quando os Africanos foram trazidos ao Ocidente. Assim, os quilts afro-americanos incorporam uma mistura única entre as tradições africanas, nativo americana e europeia.

\subsection{Design de superfície têxtil: conceitos geométricos presentes nos quilts}

O conhecimento geométrico e seus conceitos são amplamente aplicados na criação de efeitos táteis e visuais em superfícies. A manipulação do conhecimento geométrico permite aplicações criativas sobre as superfícies. Schwartz (2008) explica que a palavra superfície é de origem latina, e relaciona-se ao conceito de área/face, definida por comprimento e largura, e figurativamente à parte externa dos corpos, a aparência.

O design de superfície aplicado aos materiais têxteis pode ser classificado em categorias diversas que abrangem as estruturas para entrelaçamento de fios até os processos dispostos na superfície de têxteis já confeccionados.

Para Schwartz e Neves (2009, p. 124) o design de superfície pode ser compreendido de forma ampliada como

[...] uma atividade projetual que atribui características perceptivas expressivas à superfície dos objetos, concretas ou virtuais, pela configuração de sua aparência, principalmente por meio de texturas visuais, táteis e relevos, com o objetivo de reforçar ou minimizar as interações sensório-cognitivas entre o objeto e o sujeito. Tais características devem estar relacionadas às estéticas, simbólicas e práticas (funcionais e estruturais) dos artefatos das quais fazem parte, podendo ser resultantes tanto da configuração de objetos preexistentes em sua camada superficial quanto do desenvolvimento de novos objetos a partir da estruturação de sua superfície. 
Esta explicação diz respeito ao design de superfície de objetos e materiais variados. Referem-se a superfície como o revestimento de um objeto de volume préestabelecido, como em entalhes, estamparias e texturas sobre os suportes que envolvem objetos e também a superfície como objeto por si só, definida em simultaneidade com o volume, como é o caso do design de superfície têxtil, em tapetes, mantas, colchas, toalhas, entre outros.

Para Ruthschilling (2008) o design de superfície trata do projeto das qualidades estéticas, funcionais e estruturais da superfície de um produto, compreende a papelaria, têxtil, cerâmica atuando conjuntamente com o design cerâmico, têxtil e de estamparia.

Ao delimitar a técnica de quilt no contexto do design de superfície têxtil, podese afirmar que trata-se de um procedimento estrutural, aquele que objetiva a criação de uma superfície, quando feito por meio de remendos, e construtivo, quando elaborado por meio de aplicações sobre a superfície, pois modifica e adiciona recursos à superfície (COSTA, 2003).

Cavalcanti (2014) concorda que o conhecimento geométrico, aliado à criatividade, é um gerador de composições que exploram formatos e formas inovadoras. No caso dos quilts, esse conhecimento é fulcral, pois a composição têxtil depende da correta ordenação dos pedaços de tecido em uma forma pré-definida.

As ferramentas utilizadas na realização dos trabalhos em quilt apontam para a precisão matemática na composição e encaixe das formas, é frequente o uso de blocos de corte milimetrado e réguas de precisão para que ocorra o planejamento do encaixe das formas geométricas.

Os trabalhos em patchwork/quilt configuram mosaicos construídos com partes de tecidos "em cores e estampas variadas, que, combinadas, possibilitam a visualização de diversos padrões geométricos (quadrados, retângulos, triângulos, etc.) em sua composição, formas essas que são cuidadosamente medidas e cortadas" (SANTOS, 2012, p. 13). A geometria e a matemática surgem no discurso das artesãs de forma empírica, os conceitos são utilizados no cotidiano ainda que não exista consciência da complexidade envolvida.

Assim, no Quadro 1, apresenta-se de forma sintética, alguns dos principais conceitos geométricos aplicados na composição de quilts. 
- Composição: ação de ordenar elementos visuais de forma harmônica, expressando um sentido objetivo ou abstrato, sugerindo direção ou função.

- Módulo (Figura 5): consiste em uma unidade que é projetada com proporções específicas para agrupar-se outras unidades, de formas variadas, compondo o pavimento ou padrão (FERREIRA, 2005 apud SCHWARTZ, 2008).

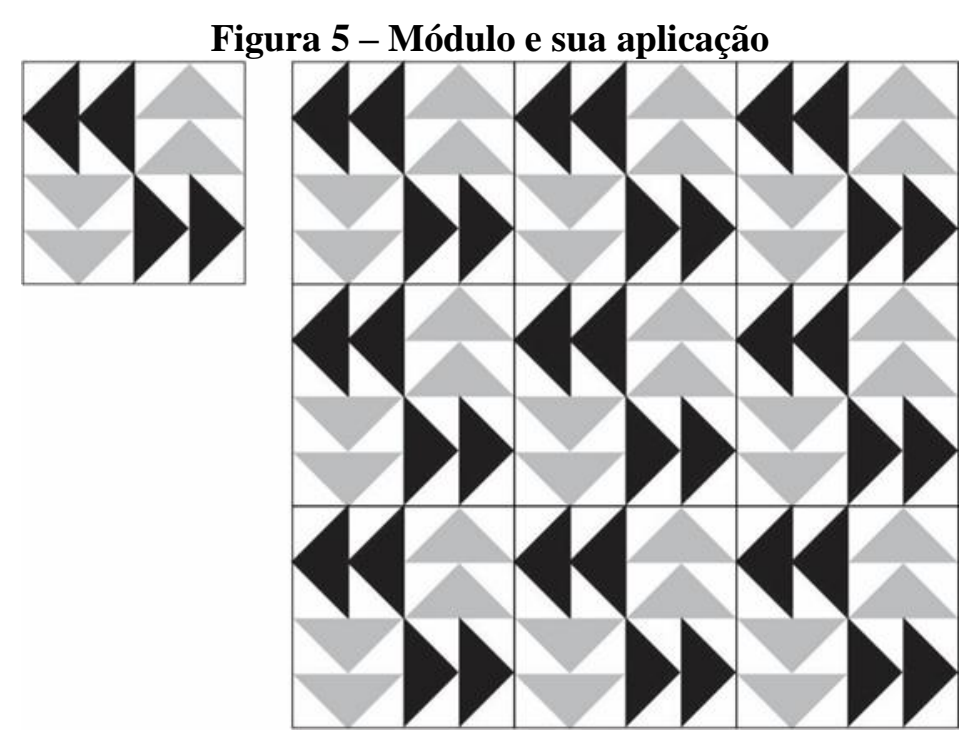

Fonte: autora (2016)

- Pavimentação do plano (Mosaicos): estrutura de repetição múltipla que apresentam agrupamentos de diversas figuras geométricas na composição (CAVALCANTI, 2014). São obtidas a partir da definição das malhas.

- Malhas/grades (Figura 6): termo do design de superfície, tratam-se de estruturas previamente definidas para disposição de módulos na superfície (CAVALCANTI, 2014). As malhas regulares formam-se com a pavimentação do plano com polígonos regulares de um só tipo, já as malhas irregulares são formadas por dois ou mais tipos de polígonos regulares. As formas fechadas no interior das malhas determinam unidades chamadas módulos. 


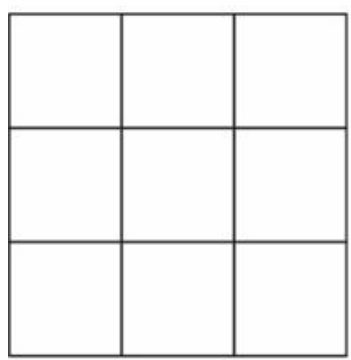

Malha regular quadrada
Figura 6 - Malhas geométricas

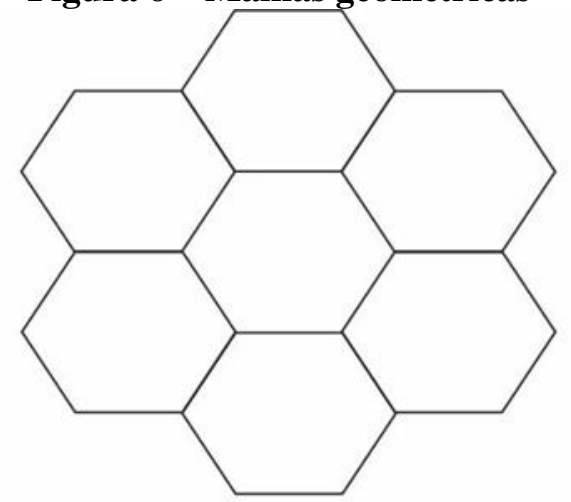

Malha regular hexagonal

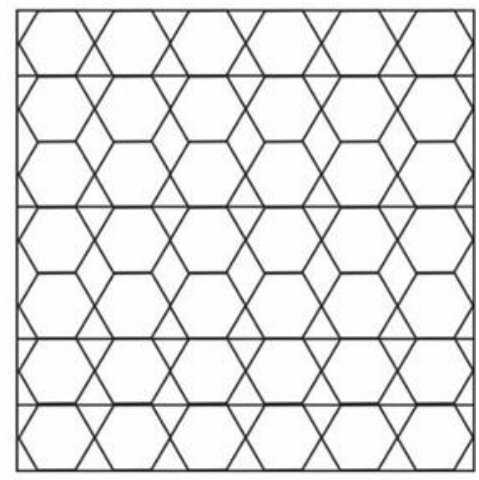

Malha semi-regular

Fonte: autora (2016)

- Simetria (Figura 7_: A simetria pode ser explicada como a repetição de uma forma de maneira ordenada e com determinado ritmo. Existem diversos tipos de simetria como de Reflexão, Rotação, Translação e Reflexão deslizante, que demanda dois movimentos. Essas simetrias, aliadas a repetições criam motivos que compõem mosaicos e padronagens.

Para Fontoura (1982) a translação ocorre quando o módulo se repete com distância de direção determinada, significa mover um objeto sem girá-lo ou refletir, com um sentido e uma distância. A rotação diz respeito ao movimento de um corpo em torno de um ponto central com ângulos pré-estabelecidos. A reflexão ou inversão se dá em função de um eixo, como em um espelho plano, o conjunto de pontos do objeto ficam em sentido oposto em relação a posição original. Cada reflexão tem um eixo "a linha do espelho". Já a reflexão deslizante combina uma reflexão com uma translação ao longo do sentido da linha do espelho. São os únicos tipos de simetria que envolvem mais de uma etapa.

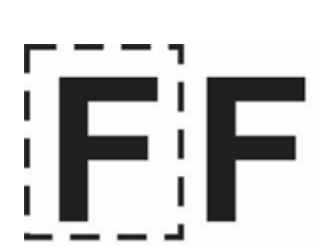

Translação

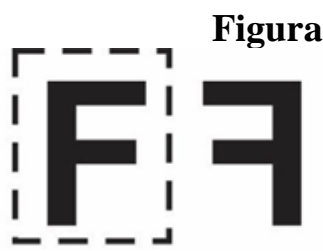

Reflexão

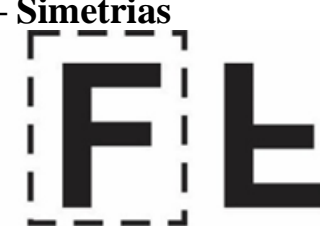

Reflexão deslizante

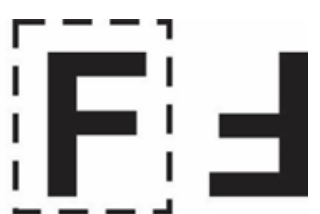

Rotação

Fonte: Adaptado de Bier (2015) 
Esses termos e conceitos elencados são essenciais para a análise dos quilts que será elaborada. Muitos outros termos fazem parte do conteúdo de design de superfície, porém, optou-se por discorrer sobre aqueles que mais se aplicam a técnica de quilt.

\subsection{A tecelagem e o quilt africano e afrodescendente}

Evidenciar a contribuição africana e afrodescendente na elaboração de ornamentos, na criação de signos e símbolos presentes no design de superfície e fazê-lo pela ótica da geometria possibilita compreender o conhecimento e cultura deste povo, que por muitos anos teve seu potencial artístico, cultural e cientifico apagado da história. Menezes $(2005$, p. 2) enfatiza que a "história brasileira pouco ou nada refletiu sobre as contribuições do africano e do afrodescendente omitindo e negando a participação do negro na construção do conhecimento e da identidade brasileira e de sua cultura material". Sobre esse aspecto, Cunha Junior (2010, p. 11) afirma que,

\footnotetext{
Até o século 16 o desenvolvimento africano era superior ao europeu em diversas áreas do conhecimento. Alguns conhecimentos técnicos e tecnológicos importantes foram desenvolvidos dentro do continente africano, outros vieram de intercâmbio com a China, Índia e com os países árabes. Importantes conquistas na matemática, como a geometria e a teoria de sistemas dinâmicos, na astronomia e mesmo na medicina foram realizadas na África
}

Cunha Junior (2010) esclarece que conhecimentos técnicos e tecnológicos sempre se difundiram por todo o continente africano devido às rotas de comércio entre os vários países africanos e as várias regiões do mundo antigo. Neste contexto se incluem os tecidos, pois no século 17 , a tecelagem africana era exportada de países africanos, como o Congo e Kano, para a Europa.

Ainda sobre a herança têxtil africana, Renne (1995 apud MAKINDE; AJIBOYE; AJAYI, 2009) destacam que a produção de tecidos artesanais, entre os povos da África, está enraizada em sua cultura, panos estes produzidos a partir da disponibilidade de insumos locais, por exemplo, algodão, seda, cortiça, lã de cabra - comumente utilizados na tecelagem.

Os conhecimentos africanos relacionados à tecelagem vão além da capacidade básica do vestir. Os africanos introduziram no Brasil a tecelagem para o fabrico de panos também para outras utilidades como redes de dormir, velas para embarcações e sacos para embalagens de produtos agrícolas e outros do gênero alimentício, eram 
responsáveis também pelo fabrico artesanal de suas vestes e de seus descendentes no Brasil colônia e império (CUNHA JUNIOR, 2010). Para o autor “[...] a tradição da confecção de redes de dormir no nordeste brasileiro permanece até hoje utilizando a forma têxtil de tear vinda da África" (CUNHA JUNIOR, 2010. p. 26).

Diversas regiões africanas são conhecidas no passado da história africana (mesmo antes de 1500) como centros importantes de produção têxtil. Destacam-se entre elas as regiões de Kano, na Nigéria, devido à produção de índigo (atual índigo Blue); a região do reino do Congo; as regiões do Madagascar e do oceano índigo, também de produção têxtil; e também as regiões do Marrocos como produtoras de tapetes e tecidos. (CUNHA JUNIOR, 2010, p. 26).

A produção de tecidos, originária da África, não se detém na fabricação essencial do referido produto, os africanos se especializaram também na etapa de tintura, fixadores de cores e trabalhos gráficos que não só adornam, mas também emitem mensagens se utilizando de suas superfícies.

A produção de quilts por africanos e afrodescendentes também tem merecido destaque na área têxtil. Nos Estados Unidos, observa-se um número significativo de publicações que abordam a produção afrodescendente de quilts, possivelmente pelo fato desta técnica fazer parte da cultura e folclore americano, porém no Brasil, esse aspecto ainda é irrisório. Hollander (1993, p. 44, tradução nossa) há mais de suas décadas apontava que "uma área importante e complexa de investigação é o estudo de colchas e outros têxteis feitos por afro-americanos"

É relevante, no relato que se segue, como características visuais assumem o "papel" de identificador de um povo. Isto leva-nos a refletir o quanto o Design de Superfície também ultrapassa a barreira de função estética.

[...] identificar características específicas de quilts feitas por quiltmakers Afro-Americanas que eram semelhantes a tecidos Africanos. No entusiasmo que se seguiu, as características visuais rapidamente vieram a ser vistas como critérios para definir um quilt Afro-Americano. O design, as técnicas e o simbolismo Africano como antecedentes para a estética dos tornou-se o foco principal para consequentes artigos, exposições, catálogos e simpósios (HOLLANDER, 1993, p. 44, tradução nossa). ${ }^{1}$

'[...] pinpoint specific characteristics of quilts made by African-American quiltmakers that were similar African-made textiles. In the enthusiasm that followed, the visual characteristics quickly came to be generally viewed as the criteria for defining an African-American quilt. African design, techniques and symbolism as antecedents for the quilting aesthetic of African-American quilters became the primary focus for ensuing articles, exhibitions, catalogs and symposia (HOLLANDER, 1993, p. 44). 
Ao longo de sua obra, Hollander (1993) fala sobre os processos de produção similares entre quilts africanos e quilts afro-americanos, atuando como características de autenticidade destes produtos. Wahlman (2001), em sua obra Signs and Symbols: African Images in African-American Quilts, destaca:

O design similar dos quilts africanos e dos quilts Afro-Americanos são coincidência, devido ao processo técnico de emenda que reduz o tecido a formas geométricas - quadrados e triângulos. Todas estas técnicas - piecing, appliqué e quilting - eram conhecidas na África, na Europa e nos Estados Unidos, no entanto, esses quilts Afro-Americanos são muitas vezes profundamente diferentes dos quilts europeus ou anglo-americanos. A diferença está nos princípios estéticos historicamente diferentes, das dimensões técnicas e religiosas (WAHLMAN, 2001, p. 26, tradução nossa). ${ }^{2}$

$\mathrm{Na}$ verdade, os quilts afro-americanos são uma mistura de tradições têxteis resultante da chegada de escravos africanos no Continente americano. Os panos que traziam consigo, tiveram suas técnicas de produção difundidas para artigos como quilts, daí a mistura de técnicas de produção.

Estes parágrafos sobre quilts, atestam a importante influência dos saberes africanos na produção de tecidos, difundida para diferentes regiões da América. Novamente, as características visuais que compõem um produto se tornam fatores de identidade cultural de um povo, servindo inclusive como marcador de aceitação, ou não, social.

\footnotetext{
Estudiosos localizaram um pequeno grupo de quilts profundamente diferentes visualmente da estética do quilt americano tradicional. Esses quilts idiossincráticos de mulheres negras do sul rural foram examinados de perto quanto as variações estilísticas, técnicas de construção, opções de cores de tecido e referências simbólicas de design. O mais emocionante era a ligação entre os quilts dos negros americanos com as tradições de design africanos, que se acredita que indicam uma memória cultural inconsciente de sua distante pátria. Quilts afro-americanos tornaram-se uma das mais novas formas de exotismo da América. [...]. Critérios visuais para reconhecer quilts afro-americanos (comprimento do ponto, organização assimétrica dos remendos, tamanho das manchas, o uso frequente de cores brilhantes) foram concebidos (BENBERRY, 1990 apud HOLLANDER, 1993, p. 48).
}

\footnotetext{
2 Similar designs in African quilted textiles and African-American quilts are coincidental, due to the technical process of piecing which reduces cloth to geometric shapes - squares and triangles. All these techniques - piecing, appliqué and quilting - were known in Africa, Europe and the United States, yet these African-American quilts are often profoundly different from European or Anglo-American qulits. The difference lies in historically different aesthetic principles, whith both technical and religious dimensions (WAHLMAN, 2001, p. 26).
}

${ }^{3}$ Scholars located a small group of quilts profoundly different visually from the accepted aesthetic of traditional American patchwork quilt. These idiosyncratic quilts from black women of rural southern and 
As características visuais são consideradas muito mais importantes que as características materiais do produto estudado, pois segundo Benberry (1990 apud HOLLANDER, 1993), a origem de um quilt, a data de produção e componentes do pano não eram, nem de longe, considerados os aspectos mais importantes para determinar a identidade de seu artesão. Bastava verificar as características visuais para saber, com certeza, se um quilt era ou não de origem afro-americana.

Hollander (1993) destaca que uma das características principais de semelhança entre os panos africanos e os quilt afro-americanos, é a presença de linguagem visual composta por símbolos na formação de padrões.

O mesmo autor também destaca o importante lugar que as cores ocupam na produção de um pano africano, ressaltando que o mais precário dos panos era azul e branco, resultando em um forte contraste que podia ser visto à distância, porém, mais tarde, panos coloridos foram produzidos fazendo-se uso de panos europeus que tinham sido desfiados e retecidos.

Padrões múltiplos, improvisação, assimetrias e cores exercem importante função em panos africanos quanto à comunicação de status social do tecelão em termos de riqueza, prestígio e educação. Ainda quanto à função estética e simbólica, Thompson também sugere que eles vão além da função de proteção, causando confusão aos espíritos maus (THOMPSON, 1969 apud WAHLMAN, 2001). Porém, segundo Wahlman (2001), estas características são relevantes principalmente para quatro civilizações africanas: os Mande (povos da África Ocidental), os Yorubá e Fon, os povos Ejagham e os povos Kongo, lembrando, mais uma vez a compra dos escravos no chamado "Novo Mundo".

Os quilts que se encontram documentados, feitos por escravos para uso próprio, são produzidos em padrões tradicionais como: "Nine-Patch" e "Log-Cabin. O "Log Cabin" são pequenos quadrados que compartilham afinidades com o pano conhecido

similar backgrounds were examined closely for stylistic variances, construction techniques, fabric color choices and symbolic design references. Most exciting of all was linkage between the black American quilts and African design traditions, believed to indicate an unconscious cultural memory in the quiltmakers of their far-way motherland. African-American quilts became one of America's newest forms of exotica. [...]. Visual criteria for recognizing African-American quilts (stitch length, asymmetrical organization of quilt patches, size of the patches, frequent use of bright colors) were devised (BENBERRY, 1990 apud HOLLANDER, 1993, p. 48). 
como "Mojo" ou "Hand". Estes últimos se originam da África Ocidental e África Central (HOLLANDER, 1993).

\section{Análise de padrões africanos e afrodescendentes}

A partir da base teórica exposta observa-se que a cultura africana influenciou a produção de tecidos e padrões, tanto das culturas em que seus povos foram inseridos pela diáspora, como de seus descendentes, como é o caso dos afro-americanos.

Nesta análise são observadas e analisadas as ocorrências de transformações geométricas em blocos denominados como Freedom Quilts, buscando evidenciar a presença do conhecimento geométrico, bem como, exemplificando por meio de imagens de artesanatos em quilt produzidos por afrodescendentes. Por meio das imagens é possível observar também que os quilts afro-americanos possuem composição estética muito específica que os diferencia dos quilts tradicionais, americanos e europeus.

A primeira análise (Figura 8) apresenta dois quilts compostos com a variação do bloco Follow the Stars, um bloco de quatro partes (Four Patch). Na imagem denominada A, o bloco aparece de forma ordenada e possui ritmo regular, aplicado por translação. Já na imagem B, o mesmo bloco aparece em tamanhos variados e numa composição assimétrica, característica nos quilts produzidos por afrodescendentes. Neste bloco é possível identificar a ocorrência de rotação, reflexão horizontal e vertical, a visualização da forma é ressaltada pela alternância de cores. Visualiza-se as formas do paralelogramo, quadrados e triângulos retângulos. 
Figura 8 - Bloco Follow the Stars: aplicação e análise

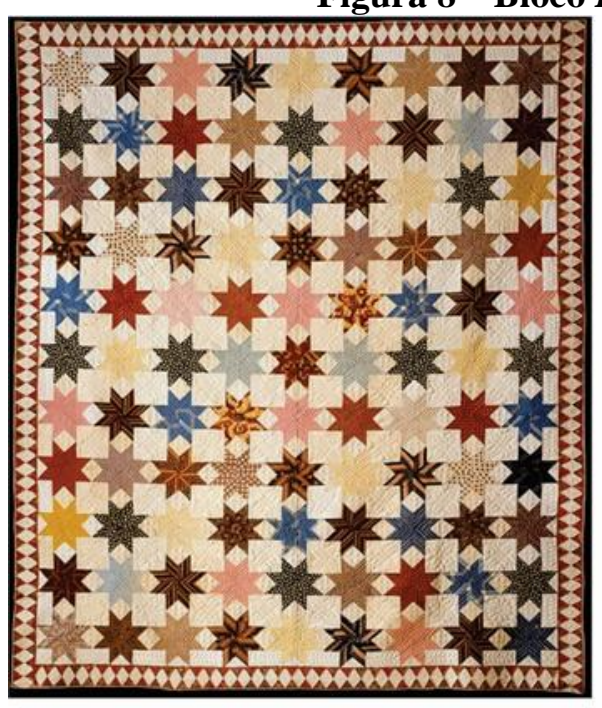

A

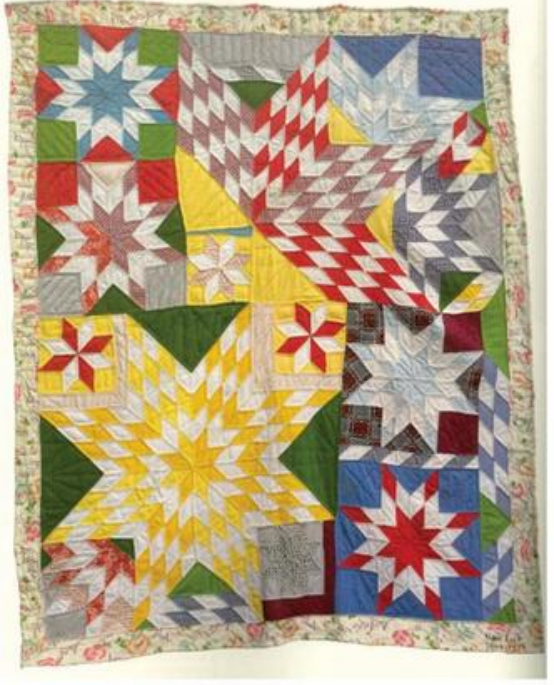

B

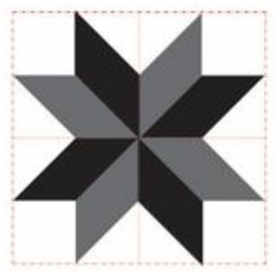

Ocorrências:

- Rotação

- Reflexão horizontal

- Reflexão vertical

Fonte: autora (2016) a partir de Davis $(1846)^{4}$ e Ezzel (1977) ${ }^{5}$ apud Wahlman (2001)

Na Figura 9 foi analisado o bloco Bear's paw e suas aplicações. Na imagem A, o bloco é aplicado de forma ordenada, também por translação, as cores são continuas em todo o trabalho, com exceção do centro, que possui outra aplicação. Já na imagem B, um quilt produzido pela afro-americana Lucinda Toomer, percebe-se a liberdade na aplicação das cores. A imagem do bloco Bear's paw pode ser visualizada, aplicada por translação, mas também encontram-se as listras e a assimetria típicas dos quilts africanos. O bloco apresenta as transformações de rotação, reflexão horizontal e vertical, observa-se a presença de quadrados e triângulos em sua composição.

\footnotetext{
${ }^{4}$ Figura 8A - Star of Lemoyne Quilt, produzido por Rebecca Davis, em 1846, com dimensão de $203.2 \mathrm{x}$ $238.8 \mathrm{~cm}$, encontra-se no The Metropolitam Museum of Art

${ }^{5}$ Figura 8B - Star quilt, produzido por Nora Ezell, em 1977, com dimensão de 238,7 x 187,9 cm, disponível no American Folk Art Museum.
} 
Figura 9 - Bloco Bear's Paw: aplicação e análise

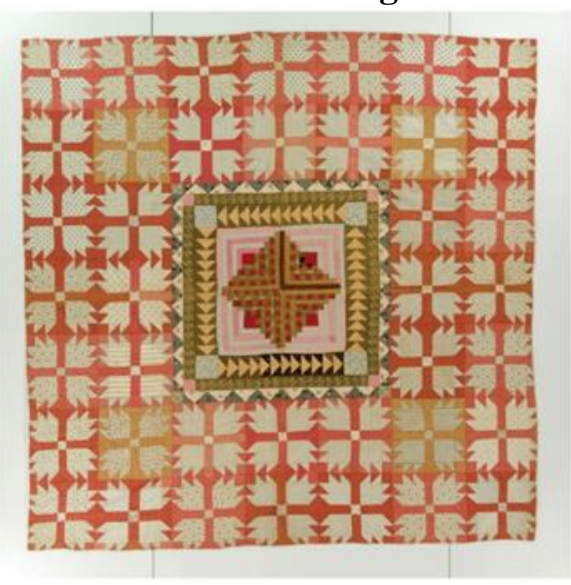

A
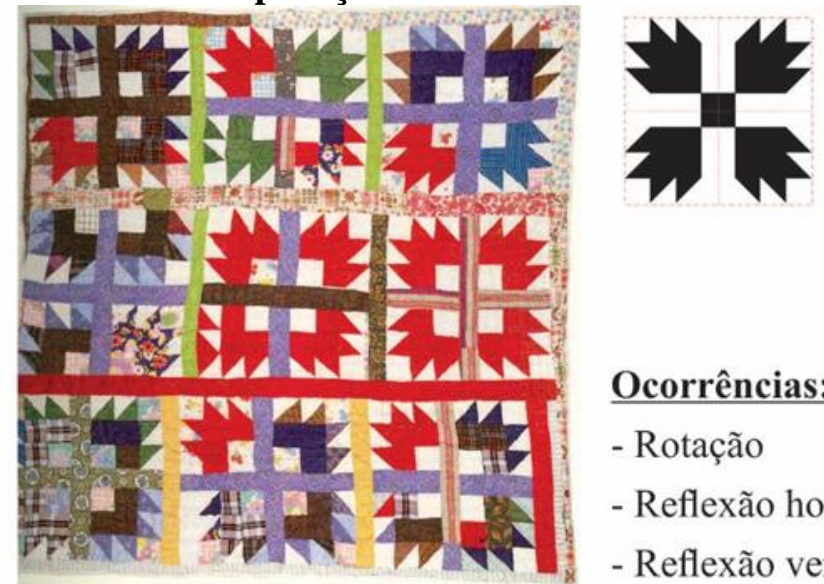

Ocorrências:

- Rotação

- Reflexão horizontal

- Reflexão vertical

Fonte: autora (2016) a partir de Museum (1880-1900) ${ }^{6}$ e Toomer (1979) ${ }^{7}$ apud Wahlman (2001)

Na Figura 10, o bloco Drunkards é aplicado na imagem A, por meio de translação ao longo da composição, a aplicação de cores mantém seu ritmo. Na imagem B tem-se uma espécie de álbum onde o bloco é aplicado em dois pontos, observa-se intervenção nas cores, o que modifica a aparência do bloco. Há a presença de tiras de tecido que emolduram os blocos. O bloco em questão apresenta a ocorrência de rotação, este bloco é o único entre os exemplos estudados que possui formas circulares, observase a presença de quadrantes de circunferência.

\footnotetext{
${ }^{6}$ Quilt denominado Bear's claw (garra de urso) de autoria desconhecida, de 1880-1900, com dimensão 181 x $183 \mathrm{~cm}$, disponível no International Quilt Study Center and Museum - Universidade de Nebrasca. ${ }^{7}$ Cotton leaf quilt, produzido por Lucinda Toomer em 1979, com dimensão de 193,0 x 180,3 cm, disponível no American Folk Art Museum.
} 
Figura 10 - Bloco Drunkards: aplicação e análise

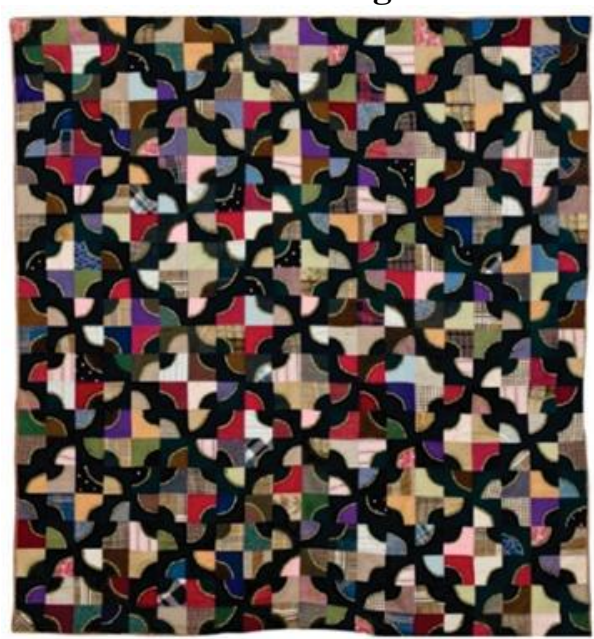

A

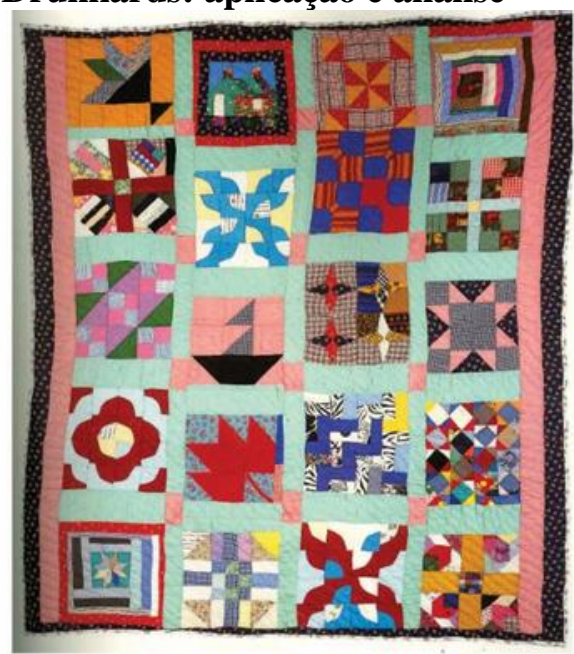

B

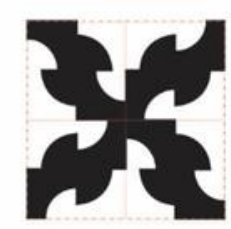

Ocorrências:

- Rotação

Fonte: autora (2016) a partir de Watson (1900) ${ }^{8}$ e Toomer (1979) apud Wahlman (2001)

\section{Considerações finais}

Os estudos em design de superfície têxtil estão se intensificando nos últimos anos no Brasil, dentro do campo cientifico do design de moda. A preocupação com o material, suas técnicas de manipulação e obtenção de superfícies e estruturas variadas se acentuou. Para Clarke (2011) isso ocorre porque muitas realizações contemporâneas inovadoras estão vinculadas ao tecido e várias culturas e tradições têm contribuído para a diversidade de técnicas aplicáveis aos tecidos.

Dentre essas técnicas encontra-se o quilt, que apesar de ser muito utilizado em produtos artesanais, possui aplicação no design de produtos de moda, não apenas em vestuários, mas também em bolsas e calçados.

O quilt é compreendido no Brasil como uma técnica de origem europeia e euro descendente, no entanto, ao estudar as origens e a produção material desta técnica evidencia-se que a cultura africana também desempenhou papel essencial em sua história e desenvolvimento. Essa parte da história é pouco conhecida em território nacional, inclusive por aqueles que pesquisam e estudam o design de moda e o design de superfície têxtil, haja vista que são raros os materiais sobre o assunto em língua portuguesa. Também deve-se ao fato de que tal técnica não está enraizada na cultura brasileira como ocorre com a norte-americana, porém acentuou-se nos últimos anos.

\footnotetext{
${ }^{8}$ Pieced Drunkard's Path Quilt, de autoria de Ella Dargan Watson, de 1900, com dimensão 168,9 x 180,8 $\mathrm{cm}$, disponível no The Charleston Museum.
} 
Apresentar a diversidade étnico racial na formação e história dessa técnica contribui com a construção do conhecimento sobre design de superfície e abre um leque de possibilidades de pesquisas sobre a cultura africana e sua produção material nas superfícies. Trazer esse tema sob a perspectiva da geometria corrobora o aspecto projetual e o apuro técnico e tecnológico que sempre esteve presente na cultura africana e, por consequência, afrodescendente pois afirma essa etnia como produtora de conhecimento. Elucidar a contribuição africana ao desenvolvimento do quilt permite compreender o conhecimento embutido e a carga cultural desse povo.

Os Freedom Quilts, tendo ou não sido utilizados como códigos nas ações de libertação de africanos e afro-americanos escravizados, constituem parte da história deste artesanato e desta arte folclórica e, como descrito por Wahlman (2001), não há dúvidas que os quilts africanos trazem consigo elementos, signos e símbolos, da cultura, da religião e do conhecimento e apuro técnico oriundos da tecelagem africana.

A realização desse estudo contribui com o campo do design de superfícies têxteis e sua história ao evidenciar a presença do conhecimento geométrico e sua aplicação, tanto na composição dos blocos individuais como nas aplicações. Isso ocorre no quilt tradicional e naqueles produzidos por afrodescendentes. No entanto, observa-se que a produção têxtil das mulheres afro-americanas possui características que os individualizam, tais características remontam as heranças culturais africanas na tecelagem. Os artefatos apresentam maior liberdade criativa, não se submetem a padronização absoluta, trazem diversificação na disposição de cores e formas, utilizamse da assimetria como recurso e reafirmam seus atores como produtores de inovação no conhecimento, na tecnologia e na técnica.

\section{Artigo recebido em Maio de 2016. Aprovado em Junho de 2016 DOI:http://dx.doi.org/105965/1982615×09182016072}

\section{Referências}

BIER, C.. Symmetry \& Pattern: The Art of Oriental Carpets. Disponível em: <http://mathforum.org/geometry/rugs/symmetry/basic.html>. Acesso em: 02 jan 2016. 
BLIGHT, David W. Passages to freedom: The Underground Railroad in history and memory. Estados Unidos: Smithsonian Books, 2004.

CAVALCANTI, Ana Helena Soares. Experimentando Superfície: uma análise das possibilidades geométricas na criação de padronagens. 2014. 249 f. Dissertação (Mestrado) - Curso de Design, Universidade Federal de Pernambuco, Recife, 2014.

CLARKE, S. Diseño textil. Barcelona: Blume, 2011.

COSTA, Maria Izabel. Transformação do Não Tecido: Abordagem de Design Têxtil em Produtos de Moda. 2003. 155 f. Dissertação (Mestrado) - Curso de Engenharia Têxtil, Departamento de Engenharia Têxtil, Universidade Federal de Santa Catarina, Florianopólis, 2003.

CUNHA JUNIOR, Henrique. Tecnologia africana na formação brasileira. Rio de Janeiro: CEAP, 2010.

DAVIS, Rebecca. Star of Lemoyne Quilt. 1846. Disponível em: <http://www.metmuseum.org/art/collection/search/13906>. Acesso em: 05 maio 2016.

EGLASH, Ron. African Fractals: Modern Computing and Indigenous Design. New Brunswick, NJ: Rutgers University Press, 2002.

FONTOURA, Ivens. De-composição da forma: manipulação da forma como instrumento para a criação. Curitiba: Itaipu, 1982. 199 p.

FUNG, Dora. Boho, Victorian Goth, Menswear: Your Ultimate Guide to Fall's Biggest Trends. 2015. Disponível em: <https://www.yahoo.com/style/boho-victorian-gothmenswear-19-c1441033552878/photo-patchwork-photo-1441046594259.html>. Acesso em: 05 maio 2016.

HOLLANDER, Stacy. C. African-American quilts: two perspectives. Folk Art, v.18, n.1, $1993 . \quad$ Disponível em: <http://www.selftaughtgenius.org/sites/stg/images/2525/African\%20American\%20Quilt s.pdf> Acesso: 10 mai 2016.

JOHNSON, Julie. History of quilting. 2015. Disponível em: <http://www.emporia.edu/cgps/tales/quilte 1.html>. Acesso em: 26 mai 2015.

MAKINDE, D. Olajide; AJIBOYE, Olusegun Jide; AJAYI, Babatunde Joseph. Aso-oke production and use among the Yoruba of Southwestern Nigeria. The journal of Pan African Studies, vol. 3, n. 3, September 2009.

MENEZES, Marizilda dos Santos. Etnogeometria: a Geometria Construída nos Panos Africanos. In: GRAPHICA, 6., 2005, Recife. Anais... . Recife: Graphica, 2005. p. 1 11 . 
MINAYO, M.C.S. Ciência, técnica e arte: o desafio da pesquisa qualitativa. In: MINAYO M.C.S., (Org.). Pesquisa Social: teoria, método, criatividade. $21^{\mathrm{a}}$ ed. Petrópolis (RJ): Vozes, 1994. p. 9-29.

MUSEUM, The International Quilt Study Center \&. Bear's Claw. 1880-1900. Disponível em: <http://www.quiltstudy.org/>. Acesso em: 10 maio 2016.

PEZZOLO, Dinah Bueno. Tecidos: história, tramas, tipos e usos. São Paulo, Senac, 2007.

ROSA, Milton; OREY, Daniel C.. Symmetrical freedom quilts: the ethnomathematics of ways of communication, liberation, and art. Revista Latinoamericana de Etnomatemática, San Juan de Pasto, v. 2, n. 2, p.52-75, jun. 2009. Disponível em: <http://www.etnomatematica.org/v2-n2-agosto2009/rosa-orey.pdf>. Acesso em: 25 mai 2015.

RÜTHSCHILLING, Evelise Anicet. Design de Superfície. Porto Alegre: Ed. da UFRGS,

2008 .

SANTOS, Ernani Martins dos. Discurso e atividade matemática de praticantes de patchwork. 2012. 178 f. Tese (Doutorado) - Curso de Psicologia Cognitiva, Universidade Federal de Pernambuco, Recife, 2012. Disponível em: $<$ http://repositorio.ufpe.br/bitstream/handle/123456789/11231/tese.finalernani.martins.dos.santos.pdf?sequence=1\&isAllowed=y>. Acesso em: 26 mai 2015.

SCHWARTZ, Ada Raquel Doederlein. Design de superfície: por uma visão projetual geométrica e tridimensional. 2008. 200 f. Tese (Doutorado) - Curso de Desenho Industrial, Universidade Estadual Paulista, Bauru, 2008.

SCHWARTZ, Ada Raquel Doederlein; NEVES, Aniceh Farah. Design de superfície: abordagem projetual geométrica e tridimensional. IN: MENEZES, MS., and PASCHOARELLI, LC., (orgs.). Design e planejamento: aspectos tecnológicos [online]. São Paulo: Editora UNESP; São Paulo: Cultura Acadêmica, 2009. 277.

SHAW, Robert. American quilts: The democratic art, 1780-2007. Estados Unidos: Sterling Publishing Company, Inc., 2009.

SIELERT, Sue. Quilt blocks. $2015 . \quad$ Disponível em: <http://www.emporia.edu/cgps/tales/quilte 1.html>. Acesso em: 27 maio 2015.

VAN HAEFF, Ruth; FLEW, Janine. Handmade Style: Quilt. Estados Unidos: Murdoch Books, 2006. 112 p.

VICTORIA AND ALBERT MUSEUM. The Tristan quilt. 2015. Disponível em: $<$ http://collections.vam.ac.uk/item/O98183/the-tristan-quilt-bed-cover-unknown/>. Acesso em: 05 jun. 2015. 
WAHLMAN, Maude Southwell. Signs and Symbols: African images in African America quilts. Atlanta: Tinwood Books, 2001.

WATSON, Ella Dargan. Pieced Drunkard's Path Quilt.1900. Disponível em: <http://www.charlestonmuseum.org/research/collection/pieced-drunkard-s-pathquilt/424276A2-28EA-47CE-8FA1-534903150410>. Acesso em: 05 mai 2016.

WELLS, Yvonne. Quilted Messages. International Quilt Study Center \& Museum. University of Nebraska-Lincoln. Disponível em: <http://www.quiltstudy.org> Acesso: 10 mai 2016.

WERTKIN, Gerard C. (Ed.). Encyclopedia of American Folk Art. Nova Iorque: Routledge, 2004. 704 p. 